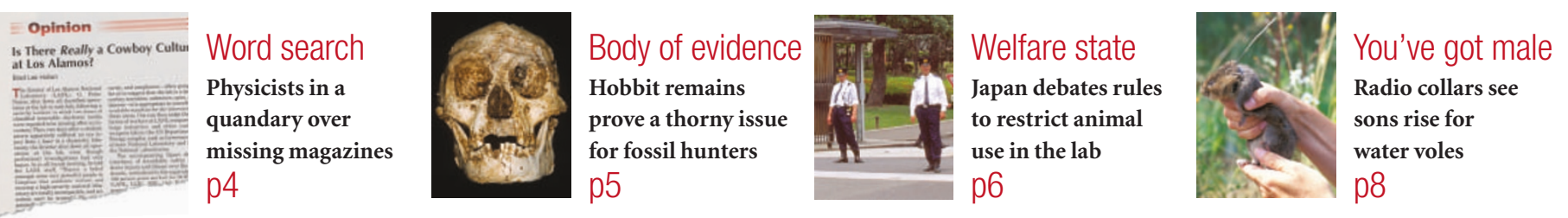

\title{
NIH workers see red over revised rules for conflicts of interest
}

Meredith Wadman, Washington

The US National Institutes of Health (NIH) is facing a revolt by employees over its tightened rules on conflicts of interest.

The restrictions, which dramatically alter a policy set up in 1995, were announced on 1 February (see Nature 433, 557; 2005). They are the result of intense pressure on the NIH from an angry Congress, after a series of embarrassing disclosures revealed that a number of senior agency scientists had been making hundreds of thousands of dollars as consultants for commercial firms.

But the move has angered NIH employees, who say that the rules go too far. They point to talented young researchers who will be discouraged from coming to the agency because their inventions have been taken up by biotechnology companies (see 'Caught between a rock and a hard place', below). And they fear for long-standing employees whose life savings could be hit hard by regulations on owning stocks.

"Many of the rules are frightening," says Abner Notkins, chief of experimental medicine at the National Institute of Dental and Craniofacial Research. "They've gone to a damaging extreme."

"The vast majority of NIH employees have done nothing wrong. We are all being punished for the transgressions of a few," adds Elaine Jaffe, chief of haematopathology at the National Cancer Institute.

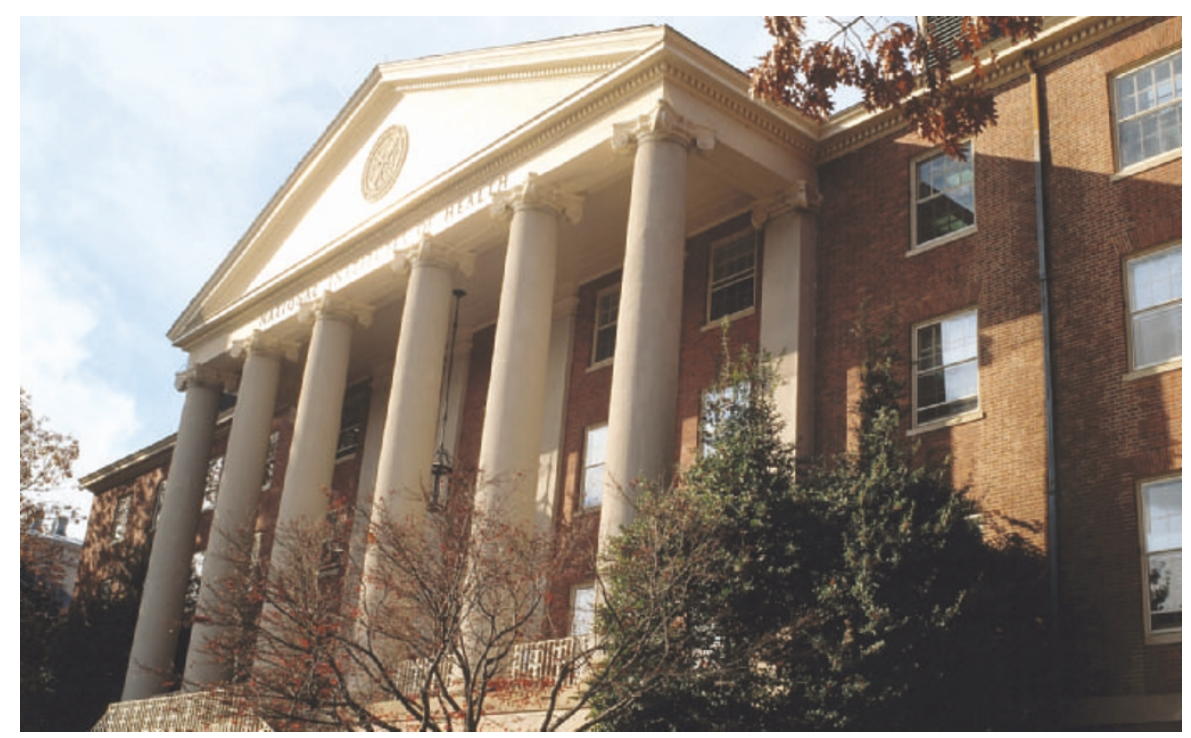

Scene of conflict: revamped ethical guidelines at the NIH are being criticized as too restrictive.

Under the rules, all forms of paid and unpaid consulting for biomedical companies are banned, and there are numerous restrictions on teaching and serving on company boards. Senior scientists are not allowed to accept academic prizes worth more than $\$ 200$. The rules also require some 6,000 senior NIH employees to sell any stock in biomedical companies owned by themselves, their spouses or their children by this July. The NIH's other 11,500 employees are each limited to $\$ 15,000$ of stocks in any given biomedical firm.

Protesters say that the rules will hurt the agency's recruiting and retention of scientists, and force significant financial losses on many employees, especially those who are past the age of easily finding another job. Notkins points out that people who bought shares in Pfizer a year ago at $\$ 37$, for example, would be obliged to sell them at the current price of $\$ 27$.

Raynard Kington, NIH deputy director,

\section{Caught between a rock and a hard place}

When Elaine Jaffe read the new ethics rules for $\mathrm{NIH}$ employees announced last month, she immediately thought of the promising young physician she was seeking to employ in her lab at the National Cancer Institute in Bethesda, Maryland.

The physician was so bright that he had already mastered the first two years of coursework by the time he entered medical school. An engineer by training, he used his spare time at medical school to invent a machine that automatically embeds, processes and sections pathology specimens. He licensed it to a small biotechnology company for whom he worked part-time while doing his medical residency. A patent is pending.

In the meantime, he applied for a two-year stint as a clinical fellow in Jaffe's haematopathology lab. He was enthusiastic about the chance to broaden his training, Jaffe says. Then the new $\mathrm{NIH}$ ethics regulations were announced.

They bar both temporary and permanent NIH employees from consulting for companies, whether or not they are paid for their services. Coming to the $\mathrm{NIH}$ would mean that the researcher couldn't be involved in steering the development of his invention. He is now reconsidering Jaffe's offer of a position.
Jaffe says that she understands why. "He won't be able to continue to work with the company to see the fruition of his effort. If they called him and they had a question about something and wanted him to take time off and come and work on something for a couple of days, he wouldn't be allowed to do it. It would stifle him creatively."

And yet, she says, "he wouldn't be working in my lab on anything related to his invention".

Jaffe says that she agrees with consulting restrictions on senior $\mathrm{NIH}$ scientists. But the ban for temporary employees is, she thinks, too much. 
counters that the rules are tough but necessary. "The preponderance of the evidence suggested that our ethics oversight system didn't work," he says. "Our number one priority was to ensure the public's trust in the integrity of the science of this agency."

He points out that, like it or not, NIH scientists can have an impact on financial markets - as they did in December, when Pfizer shares fell sharply after the National Cancer Institute halted a clinical trial amid safety concerns about the company's painkiller Celebrex.

Kington and other NIH officials have been probing the cases of some $100 \mathrm{NIH}$ scientists who congressional investigators found were not complying with the old ethics rules. It has emerged that at least half of these people did not violate the rules, but were mistakenly identified because, for example, they had the same name as another researcher who had consulted for a drug firm.

"Even if $80 \%$ of them are cleared," says Kington, "having $20 \%$ on that list who may have violated the rules says something about the system."

But hundreds of NIH employees say that the agency's response is too extreme. In an online vote last month, 700 of them elected an executive committee for the Assembly of Scientists, a dormant group of intramural scientists that has reconstituted itself to try to soften the new rules.

The revival was spearheaded by Ezekiel Emanuel, chairman of the NIH Department of Clinical Bioethics, and quickly led to a two-hour meeting late last week between the assembly's executive committee and officials including agency director Elias Zerhouni and Kington. The assembly is also consulting the American Civil Liberties Union to see whether the new rules violate the privacy and freedom-of-speech rights of NIH employees.

In the meantime, the reality of the changes is becoming apparent on the NIH campus. Last week, officials at the National Cancer Institute circulated a call for nominations for the $\$ 50,000$ Paul Marks Prize for Cancer Research, offered by the Memorial Sloan-Kettering Cancer Center in New York. "Federal employees ... could accept the honor and the plaque, but not the monetary prize," the e-mail noted.

Kington said last week that the NIH is committed to assessing the impact of the new rules on recruitment and retention, and making modifications if "an appropriate evidence base" shows that they are necessary. He asked NIH employees to "provide their input as clearly as possible". Comments from the public are being accepted until 3 April at ethics@hhs.gov.

\section{Opinion}

\section{Is There Really a Cowboy Culture of Arrogance at Los Alamos? \\ Brad Lee Holian}

The director of Los Alamos National Laboratory (LANL), G. Peter Nanos, shut down all classified operations at the lab in mid-July, following a security incident in which two items of classified removable electronic media ventory. Then, two days after a student intern apparently suffered an eye injury from a laser in a chemistry laboratory, the director shut down all operations at the lab, even though preliminary investigations had only begun. In an all-hands meeting, he told the LANL staff, -There's a belief amongst some very powerful people in Congress that academic culture and running a high-security national laboratory are totally incompatible, and sci. entists can't be trusted = He nd ? pointed $-\cdots=$ pointect arity, and complianee-often going so ar as to suggest that the lab is a den of cowboy scientists, saboteurs, spies, and thieves-it is appropriate to consult the these areas. One can then judge the behavior of workers at LANL compared to large industries and other nuclear weapons labs in the US Department (nergy complex, such as Lawrence Livdia National Laboratories. The accompanying figure shows melines of recordable safety incidents (injury and rilness) over the pas decade, normalized to the equivalent 100 person-years worked, for DOE gonnel (1)
Why then has LANL been such a target of congressional scrutiny and ire? One answer might be that since the bumbing of Hiroshima and $\mathrm{Na}$ gasaki by nuclear weapons built at Los Alamos, the lab has been the poster child of ban-the-bomb activism from the political Left, and from the lab's inception there have been calls to close it or at least terminate its nuclear weapons activity. From the political Right come the angry questions: -Why is there such a thing ? 'academic freedom' at all in a b factory? Why are any foreials anrwit ar

Paper chase: copies of a contentious article were never delivered to Los Alamos staff.

\section{Physicists miss out on critical points as magazines vanish}

Geoff Brumfiel, Washington

Some sensitive material has once again disappeared from Los Alamos National Laboratory in New Mexico - and the corridors are abuzz with theories about what happened to it.

Gone missing this time are a couple of hundred copies of the December 2004 issue of Physics Today, which contained an article critical of Peter Nanos, the laboratory's director. After many physicists at the laboratory reported that they had not received the issue, conspiracy theories began to circulate about the fate of the lost magazines.

Laboratory officials categorically deny that they are trying to keep the article from the staff. "The notion that there was some sort of an effort to keep Physics Today out of the hands of subscribers is ludicrous at best," says Jim Fallin, the laboratory's chief spokesman.

But according to an e-mail survey published in the March issue of the magazine, more than half of the laboratory's 414 subscribers say that they never received their copies of the December issue. By comparison, less than $3 \%$ say they didn't get the February 2005 issue.

The mystery of the missing magazines is just the latest reported disappearance at the laboratory: in July of last year, for example, two hard drives containing classified data were reported missing (see Nature 430, 387; 2004). The disks, together with the injury of a summer intern, led Nanos to shut down parts of Los Alamos for nearly six months and to accuse lab scientists of a "cowboy culture" of disregard for safety and security rules at the facility. Many researchers were livid about the long shutdown, especially after a government investigation concluded that the missing disks never actually existed (see Nature 433, 447; 2005).

The Physics Today article was an opinion piece by Brad Lee Holian, a theoretical physicist at the laboratory. It attacked Nanos's position by citing statistics that showed Los Alamos's safety record to be comparable to that of other national laboratories (Physics Today 57(12), 60-61; 2004). So when the issue in which it was printed failed to arrive, physicists at the lab began to speculate as to the cause of the disappearance.

"The whole thing is a mystery," says Holian. He adds that he, for one, doesn't buy the conspiracy theories: "I'm still in the camp that somebody goofed up somehow." But, he points out, the fact that rumours continue to circulate on e-mail and the popular 'LANL: The Real Story' blog shows the level of tension between staff and administrators. "After the shutdown, people don't have a lot of confidence in laboratory management anymore," he says.

Fallin doubts that Los Alamos's staff or its management are to blame for the vanishing magazines. "Mailroom employees pride themselves in their handling of Physics Today," he notes sternly. A thorough search of the lab's mail facilities has yet to turn up the missing issues, and he says a more likely explanation may be that Physics Today's mailing labels contained errors. The laboratory has contacted the postmaster-general in Albuquerque to help investigate. 